\title{
Electrochemical analysis of corrosion and wear resistance characteristics of stainless steel modified by friction reforming under micro-reciprocating frictional conditions in seawater
}

\author{
Yao ZHU*, Toshikazu FUJINO** and Tatsuhiro JIBIKI** \\ * Graduate School of Marine Science and Technology, Tokyo University of Marine Science and Technology \\ 2-1-6, Etchujima, Koto-ku, Tokyo 135-8533, Japan \\ ** Department of Marine Electronics and Mechanical Engineering, Tokyo University of Marine Science and Technology \\ 2-1-6, Etchujima, Koto-ku, Tokyo 135-8533, Japan \\ E-mail: tfujin0@kaiyodai.ac.jp
}

Received: 8 April 2018; Revised: 30 June 2018; Accepted: 11 July 2018

\begin{abstract}
As the utilization of ocean resources continues to increase, the performance and reliability of equipment used in the marine environment will become more important. Many friction and contact parts in equipment used in the marine environment directly or indirectly contribute to the service life and efficiency of various equipment and structures. Therefore, materials used in sliding parts in contact with seawater need to have both superior corrosion resistance and superior wear resistance. To develop friction-resistant materials adapted to the marine environment, the surface of $18 \mathrm{Cr}-8 \mathrm{Ni}$ austenitic stainless steel was modified to add superior properties of corrosion and wear resistance. This stainless steel was modified with silicon powders or silicon carbide powders mixed with fine high-speed-steel particles, which acted as carrier particles in a friction reforming technique. After that, zinc anticorrosive coating was applied to the modified materials by surface pressing and rubbing of a zinc pin for sacrificial corrosion protection. Corrosion and friction testing was conducted in parallel in a 3.5\% sodium chloride solution to simulate seawater under static and dynamic reciprocating motion conditions. The polarization curves and friction and wear characteristics of these modified materials were evaluated. As a result, the modified materials, especially stainless steel modified with mixed silicon and silicon carbide powders, exhibited better wear resistance than unmodified stainless steel in seawater. In addition, the corrosion rates of the modified materials and the substrate stainless steel were almost the same under the micro-reciprocating friction condition. Therefore, it was shown that the modified materials, especially stainless steel with mixed silicon and silicon carbide powders, exhibited excellent properties as friction-resistant materials in a marine environment.
\end{abstract}

Keywords : Friction reforming techniques, Stainless steel, Seawater, 3.5\% $\mathrm{NaCl}$ solution, Corrosion resistance characteristics, Wear resistance characteristics

\section{Introduction}

The utilization of marine resources is expected to increase in the future, and as a result the performance and reliability of equipment used in the marine environment has become important (Cabinet Secretariat, 2009). This equipment has many parts exposed to friction and contact, such as joints subject to very small sliding motions. Corrosion and tribological properties, primarily friction and wear characteristics, of such parts are very important because these characteristics directly or indirectly contribute to the service life and efficiency of the equipment and structures in which they are installed. Materials used in sliding parts exposed to seawater need to have both superior corrosion resistance and superior wear resistance in the marine environment. The excellent corrosion resistance of materials such as titanium alloys and stainless steels is realized by forming a thin and dense passivation film on the surface. However, the passivation film on surfaces subject to sliding motion can wear down and even be destroyed, 
negating its corrosion resistance (Iwabuchi et al., 1990). Konda et al. (2012) and Shima et al. (2014) analyzed and evaluated the corrosion and wear resistance of stainless steel coated with diamond-like-carbon (DLC) film, which has high hardness, chemical stability, and a low friction coefficient. DLC films are used industrially to provide surfaces with both excellent corrosion and wear resistance under fretting friction in seawater. Because DLC films contain pinholes, the films might become damaged because seawater can pass through the pinholes and corrode the base material. Even if there is no pinhole, similar phenomena may occur because seawater intrudes into the substrate from cracks caused by friction in seawater (Konda et al., 2012). Therefore, it is desirable to improve the corrosion and wear resistance of the substrate through a new method of replacing the DLC film.

In recent years, the authors' research group has developed a technique for creating a reformed layer containing a hard fine powder on the surface of a material by using friction (referred to as friction reforming) to improve the corrosion and wear resistances of the materials used in a sliding part (Shima et al., 2009). This study aims to use this technique to develop friction-resistant materials having corrosion and wear resistance in a marine environment. In our previous studies (Ito et al., 2010, Han et al., 2015), the surface of a stainless steel cylinder (as the substrate material) was modified with friction reforming by mainly fine silicon ( $\mathrm{Si}$ ) particles mixed with fine particles made of high-speed steel (HSS), which act as carriers to improve the wear characteristics. Friction coefficients and wear volumes of modified materials under reciprocating wear testing under dry conditions, oil-lubricated conditions, and artificial seawater were analyzed and evaluated (Han et al., 2015). As a result, the material modified with Si powder showed good wear resistance in artificial seawater, depending on the motion form and mating materials (Ito et al., 2010). In addition, the corrosion resistance of the materials modified with Si powder immersed statically in artificial seawater for 76 hours was analyzed (Ito et al., 2010). As a result, about 10 or more corrosion pits having a diameter of about $10 \mu \mathrm{m}$ were confirmed in all of the materials, but it was shown that there was no significant difference in corrosion resistance due to the reforming treatment state (Ito et al., 2010).

Typical forms of wear include corrosive wear, adhesion wear, abrasive wear, and fatigue wear (Rabinowicz, 1995). Wear is reportedly small in sliding mechanisms due to the lubricating action of seawater as the amplitude of the slip increases (Sato et al., 1986). However, another report showed that fretting wear in seawater under small-amplitude motion is much larger than that in the atmosphere, due to the electrochemical action of seawater (Waterhouse and Pearson, 1985). Therefore, even though we use the term "corrosion wear," wear characteristics vary greatly depending on the sliding conditions. Thus, to evaluate the corrosion characteristics of material subject to sliding motion, it is necessary to not only conduct static immersion corrosion testing, as in the previous study, but also to analyze and evaluate corrosion resistance under sliding conditions. Previous studies have suggested that the amount of wear is not proportional to the amount of corrosion from the static corrosion rate (Tao, 1969), but we have to consider whether the corrosion rate can be changed by friction reformation of the surface. Thus, an electrochemical approach is needed to examine the anode-cathode reaction under friction conditions.

Given this background, this study aimed to establish techniques for developing materials that have excellent corrosion and wear resistance, so they can be used in a marine environment. Thus, the corrosion resistance of stainless steel modified by friction reforming was analyzed and evaluated using an electrochemical approach, and its frictional wear characteristics were also analyzed and evaluated for reciprocating motion in seawater.

\section{Experimental analysis 2.1 Friction reforming technique}

Figure 1 shows the friction reforming techniques used in this study. A lathe and milling machine were used in the modification process. A $18 \mathrm{Cr}-8 \mathrm{Ni}$ austenitic stainless steel cylinder was mounted on the lathe and a tool with a spiral groove was set on the milling machine. The stainless steel cylinder rotating at a speed of $N_{\mathrm{R}}$ was pressed under load $W$ using a counterweight on the load table, and it was rubbed with fine powders mixed with carrier particles as the tool rotated at a speed of $N_{\mathrm{T}}$, as shown in Fig. 1(a). Concurrently, the tool was slid across the surface of the metal cylinder at speed $V_{\mathrm{T}}$. The stainless steel cylinder was modified with a continuous supply of carrier and fine particles through the groove of the tool under friction and locally high pressure. Table 1 shows typical modification conditions. Under these conditions, the temperature of the metal increased no more than a few dozens of degrees. After that, post-processing of the modified materials was conducted as shown in Fig. 1(b) to improve the surface roughness and detach loose particles from the surface. In this process, a conical tool made of tungsten carbide coated with a DLC film at the cone tip was 
used instead of the tool with a spiral groove, and it was slid across the surface of the modified material with oil lubrication.

The friction stirring process shown in Fig. 1(c) was also performed on these modified materials. This friction stirring process aimed to provide a zinc ( $\mathrm{Zn}$ ) anticorrosive coating that can exhibit a sacrificial anticorrosive effect. The modified cylinder rotating at a speed of $N_{\mathrm{T}}{ }^{\prime}=2,000 \mathrm{rpm}$ was pressed and rubbed by a Zn pin with load $W^{\prime}$, as determined by the softening temperature of the $\mathrm{Zn}$ pin. The temperature increase during the friction stirring process was comparable to that during the powder intrusion process.

The methods and conditions used in this paper were determined by repeated trial and error in the authors' previous studies (Han et al., 2015, Ito et al., 2010, Konda et al., 2012, Shima et al., 2009, 2014). These methods make it possible to form the reformed layers on the surface of the substrate for practical use.

\subsection{Specimens}

Table 2 summarizes the materials and particles we used in the surface modification. The surfaces of $18 \mathrm{Cr}-8 \mathrm{Ni}$ austenitic stainless steel cylinders were modified with the processes described in Section 2.1 to improve the corrosion and wear properties under friction. The fine powder used in this study was made of Si, which was chosen because it adheres easily to itself and the stainless steel substrate. A silicon carbide ( $\mathrm{SiC}$ ) fine powder mixed with $\mathrm{Si}$ powder was also used in anticipation of improved friction characteristics in saltwater. Reformed Si and SiC powder alone have poor fluidity, and friction reforming is difficult with only these powders, so HSS particles with an average diameter of $50 \mu \mathrm{m}$, which have good carrier fluidity, were mixed into the powders. A $\mathrm{Zn}$ pin was utilized in the friction stirring

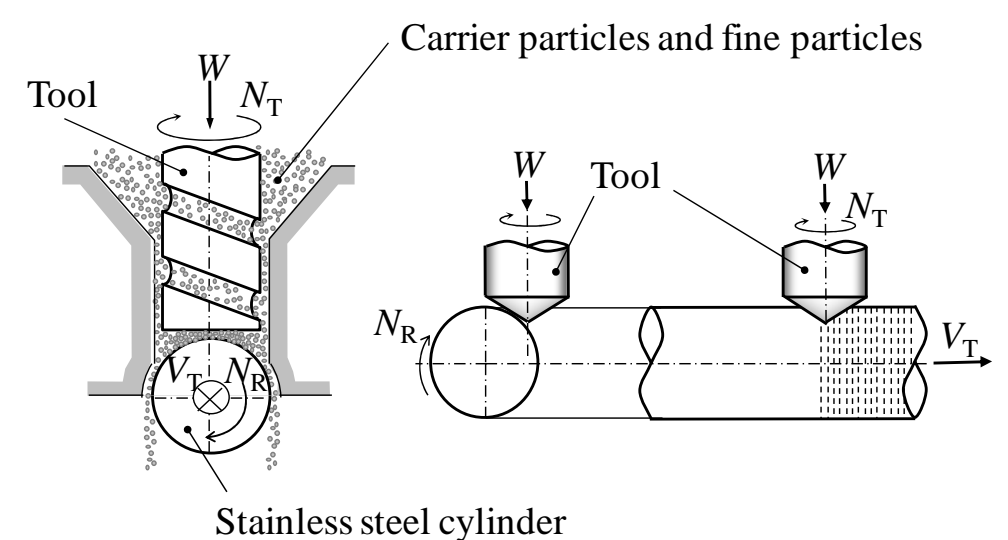

(a) Powder intrusion process

(b) Post-processing

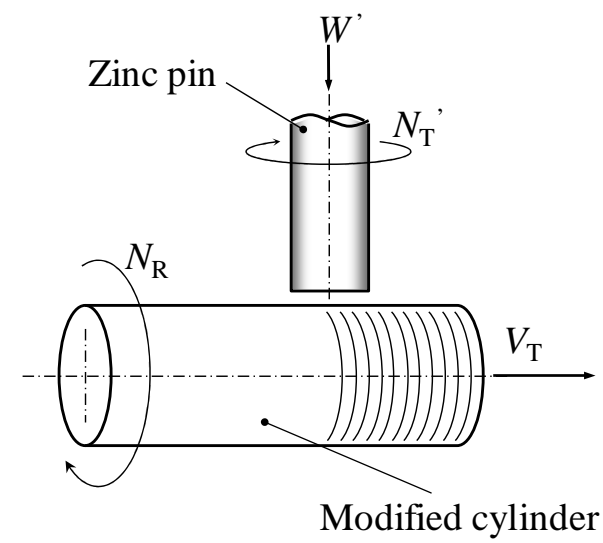

(c) Friction stirring process

Fig. 1 Friction reforming techniques used in this study. (a) A rotating stainless steel cylinder was rubbed with fine powders mixed with carrier particles. (b) In post-processing, the cylinder was rubbed with a tool to improve the surface roughness and detach loose particles from the surface. (c) Finally, the cylinder was friction-stirred with a zinc pin to provide an anticorrosive coating.

Table 1 Typical reforming conditions.

\begin{tabular}{l|c}
\hline \hline Tool & $\phi 8$ end mill (made of WC, 4 flutes) \\
\hline Load, $W$ & $98 \mathrm{~N}$ \\
\hline Tool rotation speed, $N_{\mathrm{T}}$ & $570 \mathrm{rpm}$ \\
\hline Tool traverse speed, $V_{\mathrm{T}}$ & $0.1 \mathrm{~mm} / \mathrm{s}$ \\
\hline Rotation speed of shaft, $N_{\mathrm{R}}$ & $60 \mathrm{rpm}$ \\
\hline
\end{tabular}

Table 2 Summary of materials and properties.

\begin{tabular}{l|l}
\hline \hline \multicolumn{1}{c|}{ Component } & \multicolumn{1}{c}{ Composition and properties } \\
\hline \hline Substrate & $\begin{array}{l}\text { 18Cr-8Ni austenitic stainless steel } \\
\text { (diameter 10 mm, length 120 mm,hardness vickers:HV 306) }\end{array}$ \\
\hline Fine particles & $\begin{array}{l}\text { Si }(\# 300 \text { mesh):HSS (diameter } 50 \mu \mathrm{m})=10: 90 \\
\mathrm{Si}(\# 300 \mathrm{mesh}): \mathrm{SiC}(\# 300 \mathrm{mesh}): \mathrm{HSS}(\text { diameter } 50 \mu \mathrm{m})=5: 5: 90\end{array}$ \\
\hline Metal pin & $\begin{array}{l}\mathrm{Zn} \\
(\text { external diameter } 10 \mathrm{~mm}, \text { internal diameter } 6 \mathrm{~mm}, \text { length } 30 \mathrm{~mm})\end{array}$ \\
\hline
\end{tabular}


process.

In this paper, the $18 \mathrm{Cr}-8 \mathrm{Ni}$ austenitic stainless steel substrate is referred to as stainless steel, and the surface-reformed materials using $\mathrm{Si}$ powder and $\mathrm{SiC}$ powder are referred to as stainless steel+Si and stainless steel+Si+SiC, respectively. The materials modified by the friction stirring process using the $\mathrm{Zn}$ pin are referred to as stainless steel+Si+Zn and stainless steel+Si+SiC+Zn. Figure 2 shows the stainless steel substrate and modified materials. The arithmetic average roughness $(R a)$ of the stainless steel substrate shown in Fig. 2(a) was $0.17 \mu \mathrm{m}$. The surface roughnesses $R a$ of stainless steel+Si after post-processing shown in Fig. 2(b) and stainless steel+Si+Zn after friction stirring shown in Fig. 2(c) were $3.57 \mu \mathrm{m}$ and $3.40 \mu \mathrm{m}$, respectively. The surface roughnesses $R a$ of stainless steel+Si+SiC shown in Fig. 2(d) and stainless steel+Si+SiC+Zn after friction stirring were $4.83 \mu \mathrm{m}$ and $4.27 \mu \mathrm{m}$, respectively. Modified materials after friction stirring had a slightly smaller surface roughness compared with that of modified materials after post-processing. Although the surface roughness of the modified materials was larger than that of the stainless steel substrate, the modified materials can be used with no problem in practical use in a marine environment because they have a surface roughness about the same as that of materials produced primarily by cutting work in the actual marine environment. Therefore, the friction characteristics of various modified materials obtained in this study seem to be sufficient for evaluating the characteristics of materials that are widely usable in a marine environment.

Figure 3 shows the hardness of each specimen in the depth direction obtained by the micro Vickers hardness test. The hardness of modified materials was greater than that of the stainless steel substrate between the surface and a depth of $200 \mu \mathrm{m}$. Especially, the hardness of stainless steel+Si at a distance of $40 \mu \mathrm{m}$ from the surface was the greatest among the stainless steel substrate and modified materials. However, the difference between the hardness of the modified materials and that of the stainless steel substrate was small at depths greater than $200 \mu \mathrm{m}$ from the surface, as shown in Fig. 3. From this hardness distribution, it is considered that the reformed layer was formed to a depth of about $200 \mu \mathrm{m}$ from the surface. From the previous study (Shima et al., 2009), it is considered that the structure composed mainly of $\mathrm{Si}$ was distributed non-uniformly like islands near the surface of the reformed layer of stainless steel+Si, whereas $\mathrm{Si}$ powder was mixed with the substrate material in the layers closer to the substrate.

The modified materials were cut into 10-mm lengths to conduct the corrosion and wear tests. To accurately and efficiently perform the electrochemical measurement for the stainless steel substrate without the modifications shown in Fig. 2(a), it was placed in a nitric acid $\left(\mathrm{HNO}_{3}\right)$ solution at a concentration of $10 \%$ and temperature of $60^{\circ} \mathrm{C}$ for 30 minutes to form a passive film on the surface.

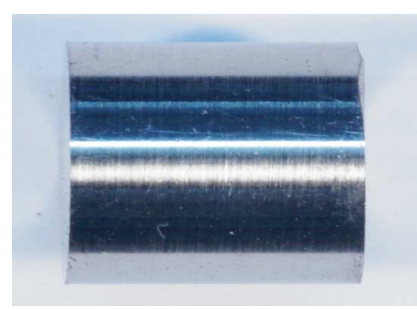

(a) Stainless steel substrate

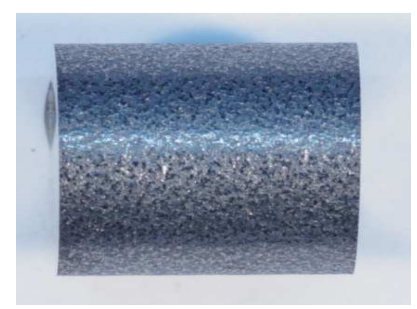

(b) Stainless steel+Si

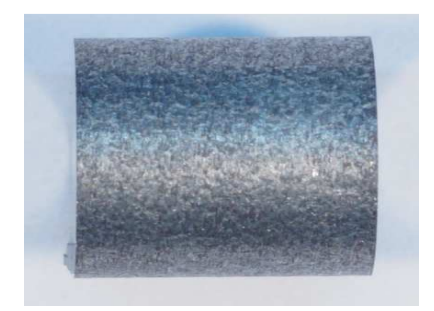

(c) Stainless steel+Si+Zn

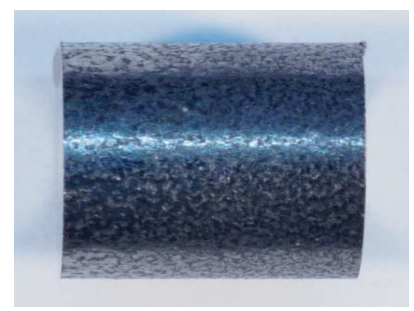

(d) Stainless steel+Si+SiC

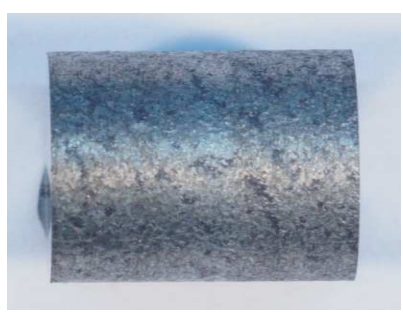

(e) Stainless steel+Si+SiC+Zn

Fig. 2 Surfaces of unreformed and friction-reformed specimens. (a) Stainless steel substrate (unreformed). (b) Stainless steel substrate reformed using Si powder mixed with HSS. (c) Stainless steel substrate reformed using Si powder mixed with HSS and coated with Zn. (d) Stainless steel substrate reformed using Si and SiC powders mixed with HSS. (e) Stainless steel substrate reformed using Si and SiC powders mixed with HSS and coated with Zn. 


\subsection{Experimental analysis system and method}

Figure 4 shows the micro-reciprocating wear and corrosion test apparatus used in this study. This equipment can perform micro-reciprocating wear and corrosion testing and take electrochemical measurements at the same time. The rotational motion of the motor was converted into a reciprocating linear motion using an eccentric mechanism. The specimen was attached to the reciprocating arm and slid against a fixed alumina counterpart with a Vickers hardness of 1,400 HV inside an acrylic tank, as shown in Fig. 4. The acrylic tank was filled with about $100 \mathrm{~cm}^{3}$ of $3.5 \%$ sodium chloride $(\mathrm{NaCl})$ solution to simulate seawater. The micro-reciprocating wear and corrosion test was conducted for $5 \mathrm{~h}$ using the crossed cylinder configuration shown in Fig. 4 (upper left). Figure 5 is a schematic diagram of the specimen mount and corrosion test apparatus. In corrosion testing, the specimen was the working electrode and an auxiliary electrode made from platinum $(\mathrm{Pt})$ was set in the acrylic tank as shown in Fig. 5. The tip of the reference electrode was made from silver/silver chloride $(\mathrm{Ag} / \mathrm{AgCl})$ and set as close as possible to the surface of the working electrode inside the tank. This reference electrode was electrically connected to the electrolytic solution via a Luggin tube filled with

Vickers hardness [HV]

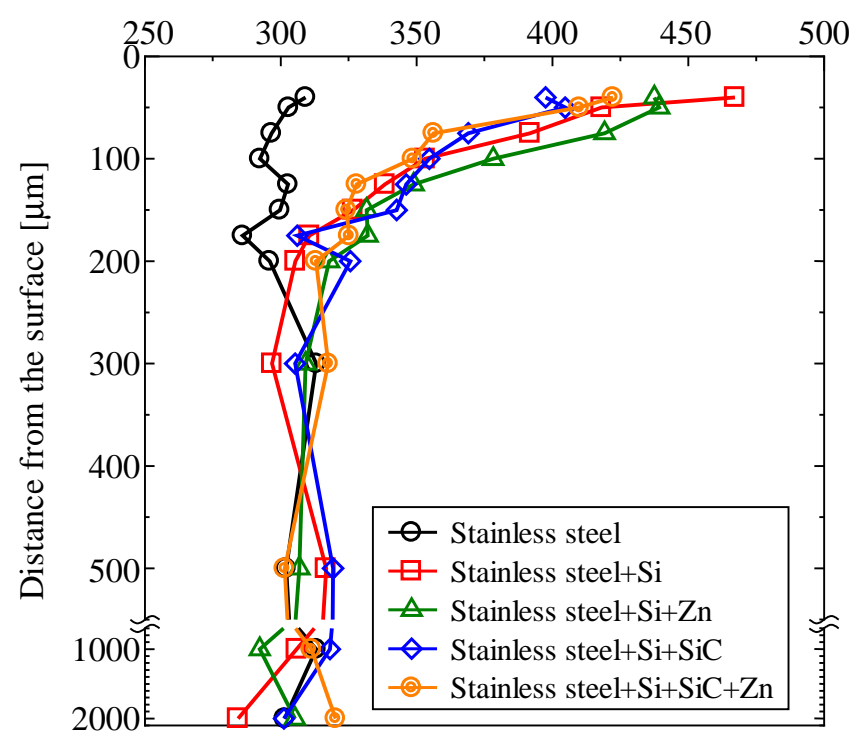

Fig. 3 Results of micro Vickers hardness testing of specimens.

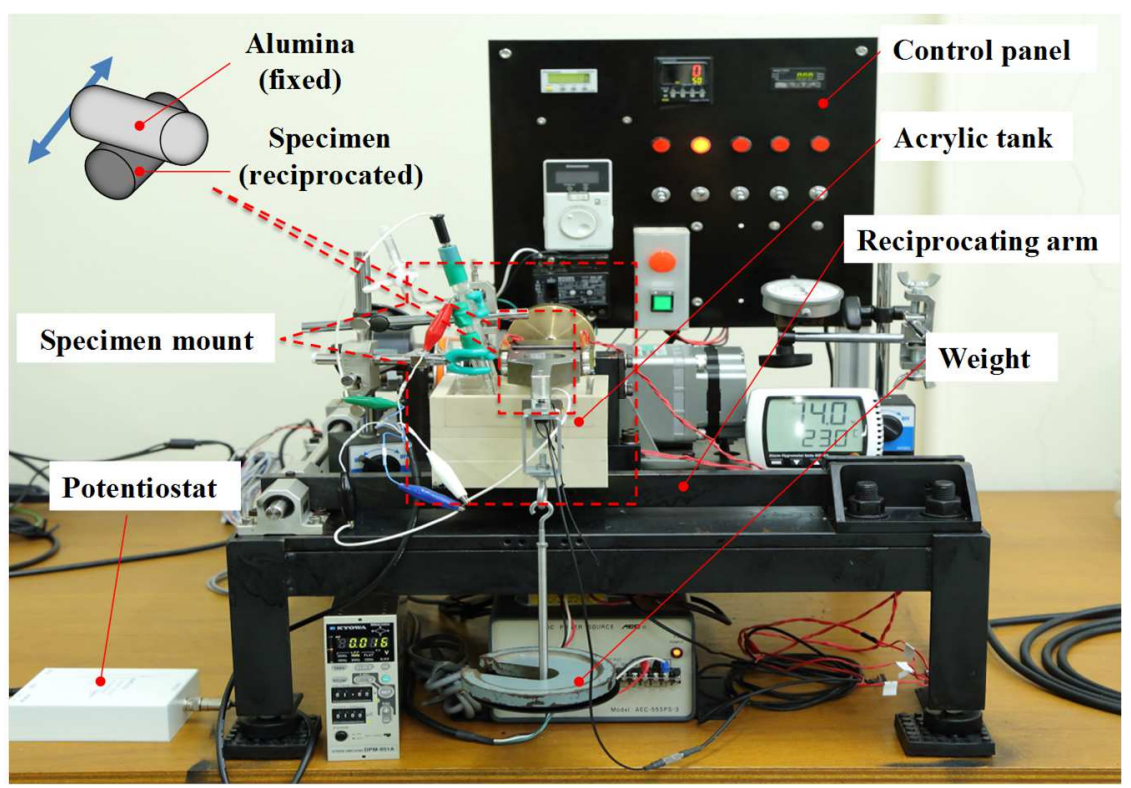

Fig. 4 Micro-reciprocating wear and corrosion test apparatus. 
saturated potassium chloride solution. When a voltage was applied, the current in each specimen in the electrolytic solution was dynamically measured at a constant sweep rate while the cylinders rubbed against each other under reciprocating motion. Tables 3 and 4 show the conditions of the wear and corrosion tests, respectively.

To evaluate the reliability of the results obtained by the electrochemical measurement system used in this study, the polarization curve of the stainless steel substrate was measured using this system and compared with curves reported in the literature (Iwabuchi et al., 1990). The results obtained by the electrochemical measurement system used in this study are considered to have high reliability because the difference between these curves was small.

\section{Results and discussion}

\subsection{Friction and wear resistance characteristics in seawater}

Figure 6 shows the relationship between the friction coefficient and the number of reciprocating cycles of the stainless steel substrate and surface-modified stainless steel. The friction characteristic of the stainless steel substrate was analyzed multiple times and confirmed to show a similar tendency. The friction coefficients of the modified steel with $\mathrm{Zn}$ coating were the lowest until 1,200 cycles. The friction coefficient of the stainless steel was about 0.6 immediately after the reciprocating sliding started, and as the number of cycles increased, its value decreased to about 0.4. The friction coefficients of the modified materials started from about 0.5 but also decreased to about 0.4 as the number of cycles increased. As an overall trend, the difference in the friction coefficients of the modified materials relative to the number of reciprocating cycles was smaller than that of stainless steel. Therefore, the modified materials

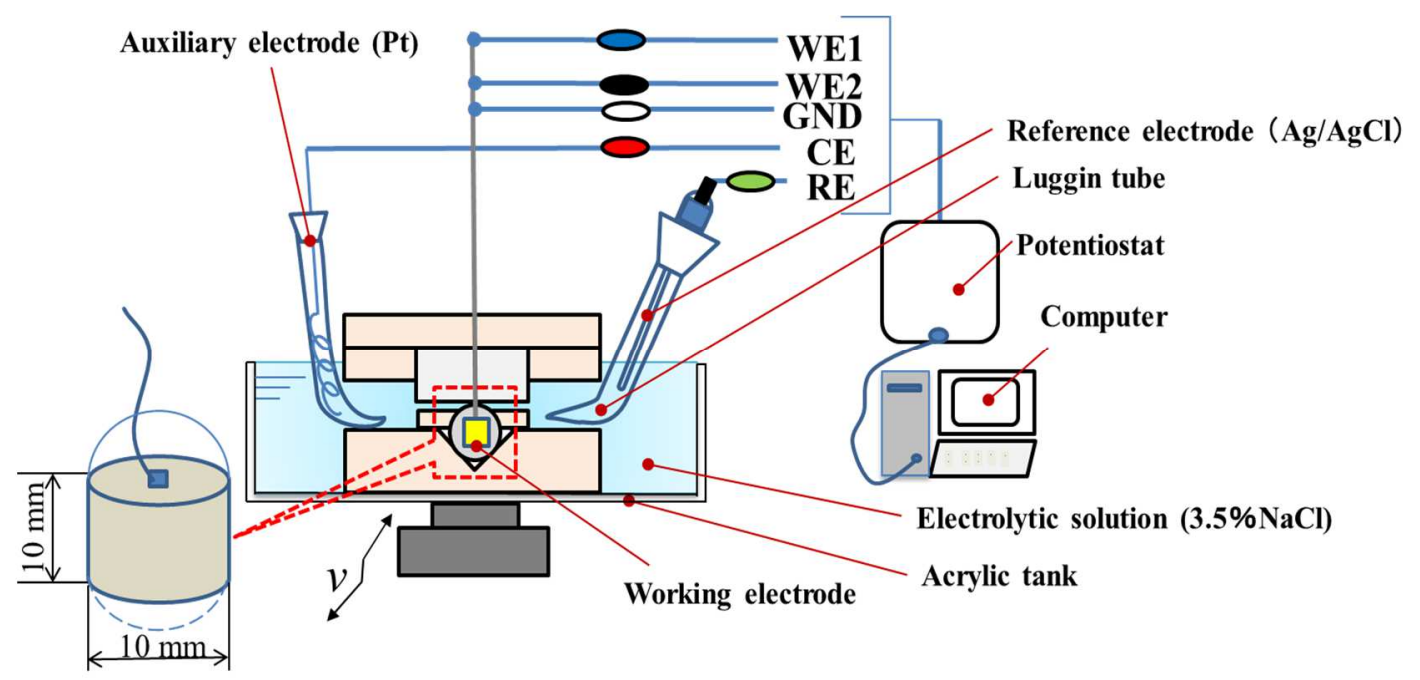

Fig. 5 Details of specimen mount and electrochemical measurement system.

Table 3 Wear test conditions.

\begin{tabular}{l|c}
\hline \multicolumn{1}{c|}{ Parameter } & Value \\
\hline \hline Atmosphere temperature & $24^{\circ} \mathrm{C} \pm 2^{\circ} \mathrm{C}$ \\
\hline Counterpart material & Alumina $(1,400 \mathrm{HV})$ \\
\hline Frequency & $1 \mathrm{~Hz}$ \\
\hline Stroke & $203 \mu \mathrm{m}-238 \mu \mathrm{m}$ \\
\hline Total number of cycles & $18,000(5 \mathrm{~h})$ \\
\hline Weight & $4.9 \mathrm{~N}$ \\
\hline Solution & $3.5 \% \mathrm{NaCl}$ \\
\hline
\end{tabular}

Table 4 Corrosion test conditions.

\begin{tabular}{l|c}
\hline \multicolumn{1}{c|}{ Parameter } & Value \\
\hline \hline Resistance of test piece & $<1 \Omega$ \\
\hline Contact area & $3.14 \mathrm{~cm}^{2}$ \\
\hline Electrolytic solution & $3.5 \% \mathrm{NaCl}$ \\
\hline $\begin{array}{l}\text { Temperature of } \\
\text { electrolytic solution }\end{array}$ & $21^{\circ} \mathrm{C} \pm 2^{\circ} \mathrm{C}$ \\
\hline Reference electrode & Luggin tube $(\mathrm{Ag} / \mathrm{AgCl})$ \\
\hline Auxiliary electrode & $\mathrm{Pt}$ \\
\hline Sweep voltage & $-1,200 \mathrm{mV}-600 \mathrm{mV}$ \\
\hline Step voltage & $\pm 0.1 \mathrm{mV} / \mathrm{s}$ \\
\hline
\end{tabular}


showed that their friction coefficients are relatively stable under reciprocating friction.

Figure 7 shows the wear scars that were observed using a microscope and the cross-sectional profiles that were measured with a surface roughness meter for each specimen. The wear volume was obtained using the size and depth of wear scars observed by the microscope. The wear volume $V$ of each specimen was calculated using the following equation, which modeled the shape of the wear scar as a quadratic surface:

$$
V=0.5 \pi a b h
$$

where $a$ is half of the wear scar width in the sliding direction, $b$ is half of the wear scar width in the direction normal to the sliding direction, and $h$ is the depth of the wear scar, as shown in Fig. 7. Figure 8 shows the wear volume of each specimen. The wear volumes of the surface-modified steels were smaller than that of the unmodified steel. This is because Si powders have high strength and excellent wear resistance (Ito et al., 2010) and strongly adhere to stainless steel. The wear volume of the stainless steel+Si+SiC specimen was smaller than that of the stainless steel+Si specimen, as shown in Fig. 8. This is because the hardness of the surface modified by powder containing ceramic SiC particles

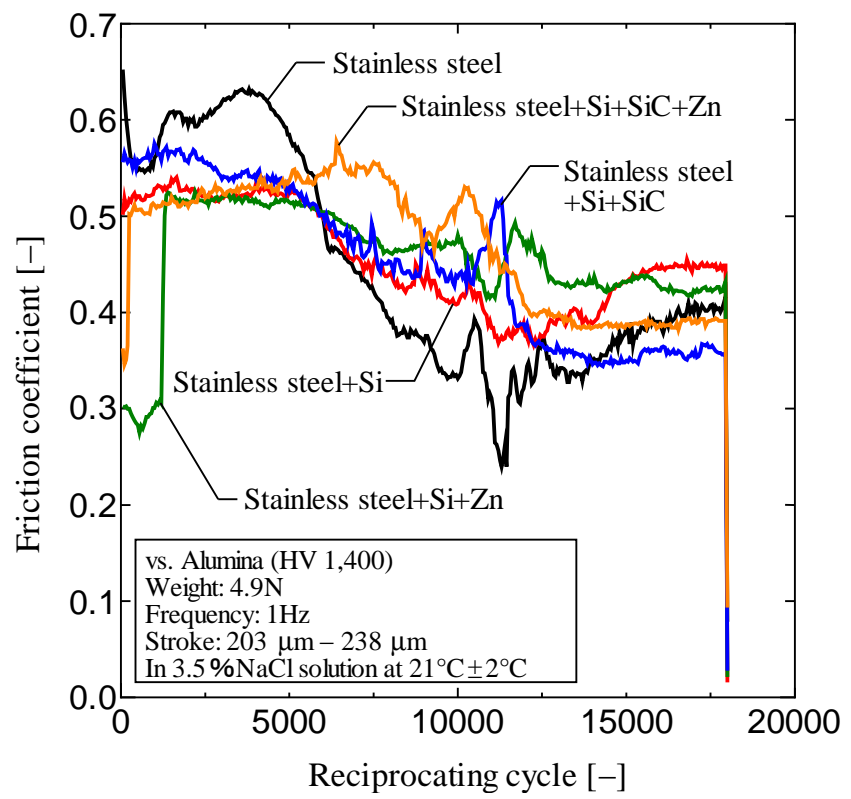

Fig. 6 Relationship between friction coefficients and reciprocating cycles for each specimen.

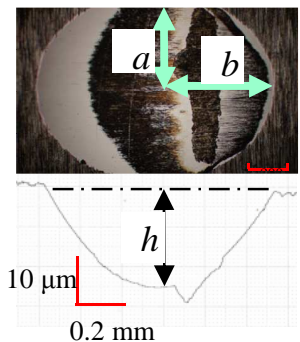

(a) Stainless steel

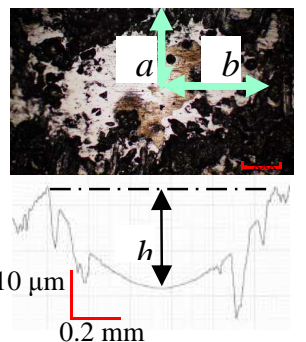

(b) Stainless steel+Si

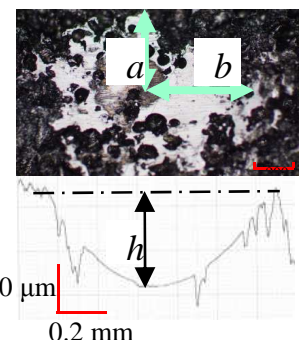

(c) Stainless steel+Si+Zn

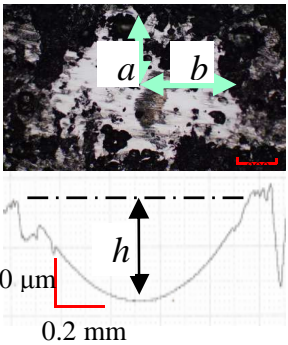

(d) Stainless steel+Si+SiC

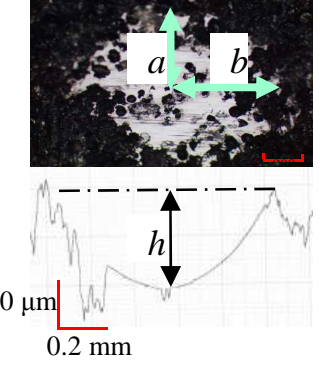

(e) Stainless steel+Si+SiC+Zn

Fig. 7 Wear scars and cross-sectional profiles of each specimen. 
(stainless steel+Si+SiC) was larger than that of the surface modified by powder without ceramic SiC particles (stainless steel+Si) because of the high hardness of $\mathrm{SiC}$, as shown in Fig. 3. Compared with the wear volume of stainless steel+Si and stainless steel+Si+Zn, or that of stainless steel+Si+SiC and stainless steel+Si+SiC+Zn, the wear volume of modified materials with the $\mathrm{Zn}$ coating was slightly larger than that of modified materials without the $\mathrm{Zn}$ coating. This is because $\mathrm{Zn}$ is softer than stainless steel, and it was peeled away first by friction.

\subsection{Corrosion resistance characteristics in seawater}

Figure 9 shows polarization curves exhibiting the relationship between current density and electrode potential for each specimen in the $3.5 \% \mathrm{NaCl}$ solution. Figure 9(a) shows the system under the static condition, that is, with the specimen and alumina in contact but not sliding, and Fig. 9(b) shows the system under the dynamic condition, that is, during the reciprocal sliding motion described in Table 3. The current density on the vertical axis of Fig. 9 was obtained by dividing the measured current by the surface area $\left(3.14 \mathrm{~cm}^{2}\right)$ of the specimen. In these figures, the corrosion current density and corrosion electrode potential of each specimen were obtained from the intersection point where the linear part of the anode and the cathode part by extrapolation using the Tafel method (McCafferty, 2005). In general, the corrosion current density is used to evaluate the corrosion rate of materials, with a higher current density indicating a faster corrosion rate. The corrosion electrode potential shown in the horizontal axis of Fig. 9 is used to evaluate the corrosion susceptibility of materials. Corrosion occurs more easily with a lower corrosion electrode potential. The current density of each modified specimen was larger and the corrosion electrode potential was smaller than those of the base stainless steel under the static condition, as shown in Fig. 9(a). These results show that the stainless steel substrate had excellent corrosion resistance to seawater under the static condition. This is because the HSS mixed in the modified surface layer corroded first.

In Fig. 9(b), the difference between the current density of stainless steel and modified materials was very small, but the corrosion electrode potential of stainless steel was the highest under the dynamic condition. Therefore, the modified materials were more susceptible to corrosion than the stainless steel substrate. However, the corrosion rates of the modified materials and stainless steel were almost the same because reciprocating friction wears away the passive film of the unmodified stainless steel. It was found that the specimens coated with $\mathrm{Zn}$ tended to corrode faster under the static condition, because $\mathrm{Zn}$ is easier to corrode than the modified surface. But under the dynamic condition, the $\mathrm{Zn}$ was completely consumed, so the corrosion rate of the modified material was almost constant.

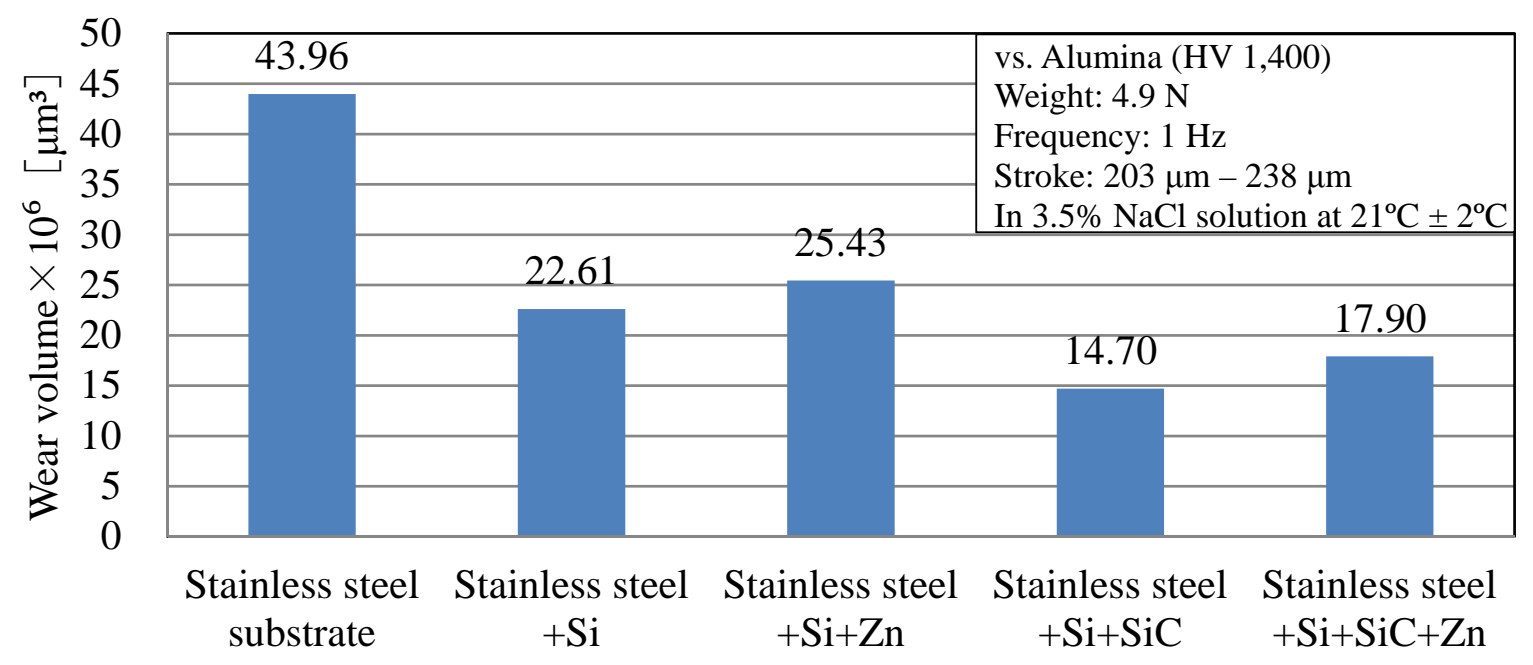

Fig. 8 Wear volume of each specimen. 


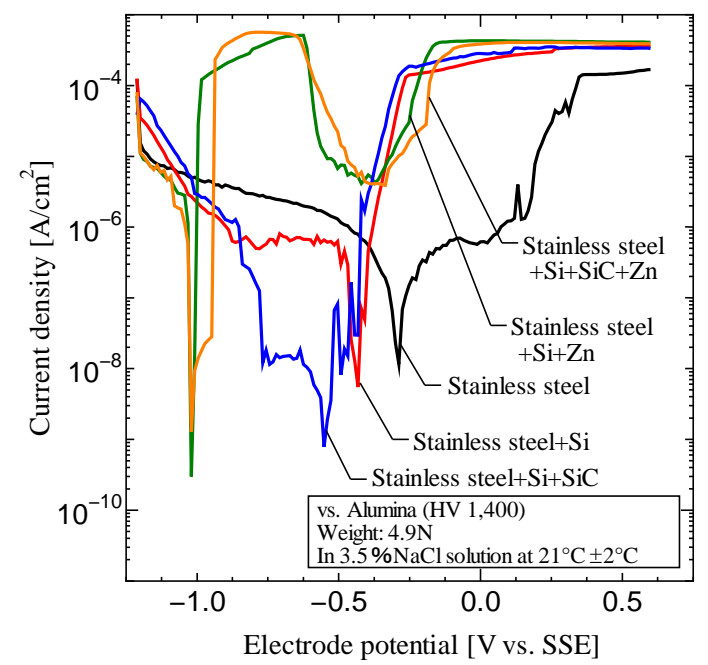

(a) Static condition

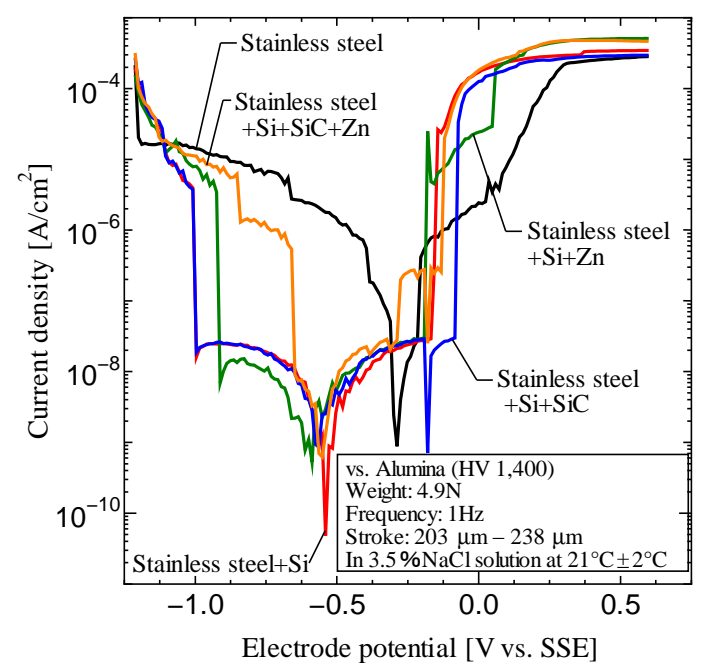

(b) Dynamic condition

Fig. 9 Polarization curves for each specimen ( $\mathrm{SSE}=$ standard silver electrode). (a) Under the static condition, where the specimen and alumina are in contact but not sliding. (b) Under the dynamic condition during reciprocal sliding motion.

\section{Conclusions}

We evaluated the corrosion resistance of $18 \mathrm{Cr}-8 \mathrm{Ni}$ austenitic stainless steel modified with $\mathrm{Si}$ and $\mathrm{SiC}$ powders mixed with HSS carrier particles by friction reforming. We analyzed the electrochemistry and friction wear of these samples after exposure to a saltwater solution under both static conditions and dynamic conditions created by micro-reciprocating motion. As a result, the following conclusions were obtained:

(1) In seawater, the modified materials exhibited better wear resistance than the stainless steel substrate. Especially, stainless steel modified with mixed $\mathrm{Si}$ and $\mathrm{SiC}$ powders had the best wear resistance.

(2) In the stationary contact condition, the unmodified stainless steel had the best corrosion resistance, but the corrosion rates of the modified materials and unmodified stainless steel were almost the same under the micro-reciprocating friction condition.

(3) Surface-modified materials, especially stainless steel with mixed Si and SiC powders, have excellent promise as friction-resistant materials for use in marine environments.

\section{Acknowledgments}

The authors thank Professor emeritus Masayuki Shima, Mr. Takashi Sugawara (research assistant), Mr. Shinji Hasegawa, Mr. Shin Okabe and Mr. Kenichiro Toyoda at Tokyo University of Marine Science and Technology for collaborating in the experimental analysis and providing valuable advice. Part of this work was supported by JSPS KAKENHI Grant Number JP17K06959.

\section{References}

Cabinet Secretariat, Headquarters for Ocean Policy, 2009 The situation of the oceans and the implemented measures by the government with regard to the oceans, (2009), pp.17-27 (in Japanese).

Han, C., Shima, M., Sugawara, T. and Jibiki, T., Wear resistance property of stainless steel modified by friction reforming, Tribology Online, Vol.10, No.2 (2015), pp.147-155.

Ito, S., Shima, M., Sugawara, T., Jibiki, T., Akita, H., Amezawa, H. and Onuki, A., Basic study on development of friction material used in seawater -Friction and wear properties of modified layer formed by rubbing power, Marine Engineering, Journal of the Japan Institute of Marine Engineering, Vol.45, No.2 (2010), pp.121-127 (in Japanese). 
Iwabuchi, A. Sasaki, T. and Hori, K., Tribological properties of SUS304 steel in seawater ( $1^{\text {st }}$ Report, Comparison of the properties in seawater with those in Air, Transactions of the Japan Society of Mechanical Engineers, Series C, Vol.56, No.53 (1990), pp.3075-3080 (in Japanese).

Konda, Y., Shima, M., Sugawara, T. and Ito, S., Fretting wear properties of DLC film coated on stainless steel -The properties and the improvement in seawater, Proceedings of the Tribology Conference 2012 Spring Tokyo (2012), pp.131-132 (in Japanese).

McCafferty, E., Validation of corrosion rates measured by the Tafel extrapolation method, Corrosion Science, Vol.47, Issue12 (2005), pp.3202-3215.

Rabinowicz, E., Friction and Wear of Materials -Second Edition, (1995), Wiley-Interscience.

Sato, J., Shima, M. and Takeuchi, M., Fretting wear in seawater, Wear, Vol.110 (1986), pp.227-237.

Shima, M., Huang, T., Konda, Y., Sugawara, T. and Jibiki, T., Fretting wear of DLC film coated on SUS304 stainless steel -The wear property in seawater and its improvement, Marine Engineering, Journal of the Japan Institute of Marine Engineering, Vol.49, No.2 (2014), pp.98-105 (in Japanese).

Shima, M., Jibiki, T., Sugawara, T., Ito, S. and Akita, H., Hard film formed on cylindrical surfaces by rubbing and their friction and wear properties, Journal of Japanese Society of Tribologists, Vol.54, No.5 (2009), pp.343-351 (in Japanese).

Tao, F. F., A study of oxidation phenomena in corrosive wear, ASLE Transactions, Vol.12, No.2 (1969), pp.97-105.

Waterhouse, R. B. and Pearson, R. B., Fretting wear of steel ropes in seawater -the effect of cathodic protection, ed. by LUDEMA, K. C., Proceedings of the International Conference on Wear of Materials (1985) Vancouver, p.79, American Society of Mechanical Engineers. 